\title{
KOMPARASI METODE SIMPLE ADDITIVE WEIGHTING (SAW) DAN ANALYTICAL HIERARCY PROCESS (AHP) UNTUK PEMILIHAN STAF LABORATORIUM KOMPUTER STMIK WIDYA CIPTA DHARMA SAMARINDA
}

\section{COMPARATIVE METHODS SIMPLE ADDITIVE WEIGHTING (SAW) AND ANALYTICAL HIERARCHY PROCESS (AHP) FOR ELECTION STAFF LABORATORY COMPUTER STMIK WIDYA CIPTA DHARMA SAMARINDA}

\author{
Salmon \\ Sistem Informasi, STMIK Widya Cipta Dharma \\ Jl. Prof. M. Yamin No.25, Samarinda \\ email : sal.rst13@gmail.com \\ Bartolomius Harpad \\ Sistem Informasi, STMIK Widya Cipta Dharma \\ Jl. Prof. M. Yamin No.25, Samarinda \\ email : arvenusharpad@gmail.com
}

(Diterima: 01-02-2018; Direvisi: 24-06-2018; Disetujui terbit: 27-06-2018)

\begin{abstract}
Abstrak
Tugas utama dari staf laboratorium komputer diantarannya: pelayanan administrasi praktikum, persiapan praktikum, pengrekrutan dan pembinaan asisten laboratorium komputer, memantau serta mengawasi pelaksanaan praktikum dan ujian praktikum. Pemilihan staf laboratorium saat ini dilakukan hanya penunjukan langsung oleh pihak pimpinan sehingga kinerja staf kurang baik karena staff yang dipilih tidak sesuai dengan keahlian yang dimilikinya. Dari permasalahan tersebut akan diangkat penelitian Komparasi Metode Simple Additive Weighting (SAW) dan Analytical Hierarcy Process $(A H P)$ Untuk Pemilihan Staf Laboratorium Komputer Pada STMIK Widya Cipta Dharma Samarinda. Hasil komparasi yang dihasilkan dari metode Simple Additive Weighting (SAW) dan metode Analytical Hierartical Process (AHP) merekomendasikan metode Analytical Hierartical Process (AHP) yang tepat dalam Pemilihan staff laboratorium, dimana metode Analytical Hierartical Process (AHP) dianggap tepat untuk mewakili pemikiran alamiah yang cenderung mengelompokkan elemen sistem ke level-level yang berbeda dari masing-masing level berisi elemen yang serupa sehingga lebih baik digunakan untuk pemilihan staff laboratorium yang melibatkan banyak kriteria dengan level hirarki yang berbeda. Selain itu, metode AHP juga menyediakan skala pengukuran dan metode untuk mendapatkan prioritas untuk semua hirarki kriteria, karena masing masing kriteria memiliki prioritas yang tidak sama.

Kata kunci : Komparasi, Simple Additive Weighting (SAW), Analytical Hierarcy Process (AHP), Pemilihan Staf Laboratorium Komputer.
\end{abstract}

Abstract

The main tasks of the computer laboratory staff are: practical administration services, preparation of practicum, recruitment and guidance of computer lab assistants, monitoring and supervising the implementation of practicum and practice test. Selection of laboratory staff at this time made only direct appointment by the leadership so the performance of staff is not good because the selected staff not in accordance with the expertise it has. From these problems will be raised research Comparative Method of Simple Additive Weighting (SAW) and Analytical Hierarcy Process (AHP) For Selection of Computer Laboratory Staff In STMIK Widya Cipta Dharma Samarinda. The comparative results resulting from the Simple Additive Weighting (SAW) method and the Analytical Hierartical Process $(A H P)$ method recommend the appropriate Analytical Hierartical Process (AHP) method in the Selection of laboratory staff, where the Analytical Hierarchical Process (AHP) method is considered 
appropriate to represent natural thinking tend to group system elements to different levels of each level containing similar elements so it is better to use for the selection of laboratory staff that involves many criteria with different hierarchy levels. In addition, the AHP method also provides measurement scales and methods to get priority for all hierarchy criteria, since each criterion has unequal priorities.

Keyword :Comparative, Simple Additive Weighting (SAW), Analytical Hierarchy Process (AHP), ComputerLaboratory Staff Selection

\section{PENDAHULUAN}

Lembaga pendidikan Sekolah Tinggi Manajemen Informatika dan Komputer Widya Cipta Dharma Samarinda merupakan yayasan yang berpartisipasi aktif dalam penyiapan dan pengadaan Sumber Daya Manusia (SDM) yang berkualitas dengan dasar pengetahuan manajemen dan ilmu komputer yang memadai. Dalam perkembangannya STMIK Widya Cipta Dharma Samarinda dibantu unsur pelaksana akademik yang salah satunya adalah bagian laboratorium komputer.

Laboratorium komputer STMIK Widya Cipta Dharma Samarinda merupakan wadah atau tempat mahasiswa kuliah untuk matakuliah praktikum, dimana persentasi matakuliah teori dan praktikum pada kampus STMIK Widya Cipta Dharma Samarinda adalah teori 40 $\%$ dan praktikum $60 \%$. Waktu pelaksanaan matakuliah praktikum setiap semesternya untuk 1 sks dilaksanakan 1 jam 30 menit perminggu selama 8 kali pertemuan dan untuk 2 sks dilaksanakan 2 jam perminggu selama 16 kali pertemuan.

Saat ini terdapat 4 (empat) laboratorium komputer STMIK Widya Cipta Dharma Samarinda yaitu laboratorium pemrograman sebanyak 63 unit PC, laboratorium aplikasi \& komputasi sebanyak 45 unit PC, laboratorium aplikasi profesional sebanyak 32 unit PC dan laboratorium jaringan komputer sebanyak 25 unit PC. Dengan pengaturan jadwal matakuliah praktikum yang sangat padat dari hari senin sampai dengan hari sabtu dari jam 08.00 sampai dengan jam 22.00 dengan jumlah mahasiswa yang mengambil matakuliah praktikum setiap minggunya kurang lebih 1500 mahasiswa, maka sangat diperlukannya staf laboratorium yang sesuai dengan kriteria penilaian yang telah ditentukan oleh pihak laboratorium komputer STMIK Widya Cipta Dharma Samarinda, dimana jumlah staf saat ini berjumlah 2 (dua) orang.

Dalam penentuan staf laboratorium komputer pihak manajemen mengalami kesulitan didalam menentukan staf yang tepat untuk diposisikan pada laboratorium komputer mengingat banyaknya pelamar dari tingkat pendidikan yang sama. Untuk itu diperlukan suatu Sistem Pendukung Keputusan (SPK) yang dapat memperhitungkan segala kriteria yang mendukung pengambilan keputusan guna membantu, mempercepat dan mempermudah proses pengambilan keputusan untuk pemilihan staf laboratorium komputer yang tepat.

Pada penelitian ini terdapat penelitian sebelumnya yaitu Joko Usito Nugroho, membahas tentang penilaian proses belajar mengajar dengan metode yang digunakan untuk mendukung penilaian proses belajar mengajar adalah Simple Additive Weighting (SAW). Ada sembilan indikator penilaian yang digunakan dalam tesis ini yakni, (1) tingkat kehadiran mengajar, (2) ketepatan memulai dan mengahiri kuliah, (3) ketepan materi dan silabus, (4) kemudahan penyampaian materi untuk 
dipahami, (5) memotivasi belajar dalam mendalami mata kuliah, (6) penggunaan ilustrasi/alat bantu untuk memperjelas materi, (7) melayani dan memberi perhatian dalam komunikasi dua arah, (8) membantu, akomodatif, dan mudah untuk di temui, (9) memiliki pengetahuan aktual dalam pembelajaran. Hasil penelitian dapat mendukung keputusan pada Penilaian proses belajar mengajar menggunakan kriteria yang telah ditentukan dan proses lain yang terkait dalam penilaian proses belajar mengajar.

Pada penelitian Syamsul Huda, membahas mengenai suatu penelitian pemilihan lokasi yang optimal dengan menggunakan metode hybrid dari pengambilan keputusan multi kreteria (MCDM) yang menggunakan fuzzy analytical hierarchy process dan analytical hierarchy process secara bersama-sama sehingga memungkinkan untuk memperoleh lokasi yang optimal. Dengan menggunakan metode hybrid dan bantuan model yang mempertimbangkan faktor objektif, faktor kritis dan faktor subjektif sebagai faktor utama dalam analisa pemilihan lokasi diharapkan diperoleh keputusan penempatan lokasi yang optimal, sehingga membuat puas bagi pembuat keputusan..

Pada penelitian Tominanto, membahas untuk memacu kinerja dokter dengan melakukan evaluasi kinerja. Penelitian ini menggunakan metode Analytical Hierarchy Process (AHP) untuk penentuan prestasi kinerja dokter. Sistem ini menggunakan kriteria dan intensitas yang ditentukan oleh pengguna, diproses denganperhitungan AHP, dan menghasilkan daftar penilaian prestasi kinerja dokter. Hasil pengujian sistem pendukung keputusan ini menyatakan bahwa sistem telah berjalan dengan benar, sehingga sistem ini dapat digunakan untuk membantu pimpinan dalam mengambil keputusan penilaian kinerja dokter yang lebih obyektif.

Sedangkan pada penelitian ini, membahas pemilihan staf laboratoium komputer menggunakan metode Simple Additive Weighting (SAW) dan Analytical Hierarchy Process (AHP). Terdapat 6 kriteria yang menjadi penilaian dalam penelitian ini yaitu:

a. Usia,

b. Tes Pengetahuan Komputer

c. Praktek Instalasi Jaringan,

d. Tes Kepribadian,

e. Tes Manajemen Server, Pendidikan.

Masalah yang ada pada penelitian ini adalah :

1. Sulit untuk menentukan staf yang tepat untuk diposisikan pada laboratorium komputer karena saat ini hanya menggunakan satu atribut/kriteria yaitu tes pengetahuan komputer.

2. Belum ada metode yang digunakan di laboratorium komputer STMIK Widya Cipta Dharma Samarinda dalam pemilihan staf laboratorium komputer saat ini.

3. Belum ada aplikasi sistem penunjang keputusan yang digunakan bagian Laboratorium Komputer STMIK Widya Cipta Dharma Samarinda untuk pemilihan staf laboratorium komputer.

Tujuan penelitian ini adalah: membandingkan metode Simple Additive Weighting (SAW) dan Analytical Hierarchy Process (AHP) dalam mendukung keputusan untuk pemilihan staf laboratorium yang tepat.

\section{LANDASAN TEORI}

Penelitian mengenai Metode Simple Additive Weighting (SAW) dan Analytical 
Komparasi Metode Simple Additive Weighting (SAW) dan Analytical Hierarchy Process (AHP) Untuk Pemilihan staff laboratorium Komputer STMIK Widya Cipta Dharma Samarinda Salmon dan Bartolomius Harpad

Hierarchy Process (AHP) banyak ditemukan dalam buku maupun jurnaljurnal ilmiah diantaranya adalah :

1. Sistem Pendukung Keputusan Penilaian Proses Belajar Mengajar Menggunakan Metode Simple Additive Weighting (SAW) (Nugroho Joko Usito, 2013)

2. Aplikasi Optimasi Pemilihan Lokasi Yang Optimal Dengan Hybrid Analysis Fuzzy Analytical Hierarchy Process (Huda, Syamsul,2011)

3. Sistem Pendukung Keputusan Dengan Metode Analytical Hierarchy Process (AHP) Untuk Penentuan Prestasi Kinerja Dokter Pada RSUD. Sukoharjo (Tominanto, 2012)

\section{Sistem Pendukung Keputusan (Decision Support System)}

Sistem Pendukung Keputusan atau Decision Support System (DSS) pertama kali diungkapkan pada awal tahun 1970 oleh G. Anthony Gorry dan Michael S. Scott Morton dalam jurnal "A Framework for Management Information System”. Gorry dan Scott Morton mendasarkan kerangka kerjanya pada jenis keputusan menurut Simon dan tingkat menajemen dari Robert N. Anthony yang menggunakan istilah strategic planning, management control dan operational control (perencanaan strategis, kontrol manajemen, dan kontrol operasional). Berikut ini beberapa definisi tentang Sistem Pendukung Keputusan:

a. Sistem Pendukung Keputusan adalah suatu sistem informasi berbasis komputer yang menghasilkan berbagai alternatif keputusan untuk membantu manajemen dalam menangani berbagai permasalahan yang terstruktur ataupun tidak terstruktur dengan menggunakan data dan model. (Turban, 2005) b. Sistem Pendukung Keputusan merupakan suatu sistem interaktif, yang membantu pengambil keputusan melalui akses secara mudah untuk memecahkan masalah yang semi terstruktur. (Ravindranath, 2003)

c. Sistem Pendukung Keputusan merupakan sistem berbasis komputer yang mendukung proses pengambilan keputusan bagi manajer atau pengambil keputusan dalam organisasi melalui pemilihan keputusan dengan dukungan data organisasi dan proses pemodelan. (Sauter, 2010)

d. Sistem Pendukung Keputusan adalah suatu sistem yang membantu menajer atau sekelompok kecil manajer memecahkan suatu masalah. Misalnya DSS yang dirancang untuk membantu manajer penjualan untuk menentukan tingkat komisi terbaik bagi para tenaga penjualannya. (McLeod, 2007 )

Dari definisi-definisi diatas maka dapat diambil kesimpulan bahwa Sistem Penunjang Keputusan adalah suatu sistem yang berbasis komputer yang ditujukan untuk membantu pengambil keputusan dalam memanfaatkan data dan model tertentu untuk memecahkan berbagai persoalan yang bersifat semi terstruktur.

Definisi awal DSS menunjukkan DSS sebagai sebuah sistem yang dimaksudkan untuk mendukung para pengambil keputusan manajerial dalam situasi keputusan semi terstruktur. DSS dimaksudkan menjadi alat bantu bagi para pengambil keputusan untuk memperluas kapabilitas mereka, namun tidak untuk menggantikan penilaian mereka. DSS ditujukan untuk keputusan-keputusan yang memerlukan penilaian atau pada keputusan-keputusan yang sama sekali tidak dapat didukung oleh algoritma (Turban, 2011). 


\section{METODE PENELITIAN}

\section{Metode Simple Additive Weighting (SAW)}

Metode Simple Additive Weighting (SAW) sering juga dikenal istilah metode penjumlahan terbobot. Konsep dasar metode Simple Additive Weighting (SAW) adalah mencari penjumlahan terbobot dari rating kinerja pada setiap alternatif pada semua atribut. Metode Simple Additive Weighting (SAW) membutuhkan proses normalisasi matriks keputusan (X) ke suatu skala yang dapat diperbandingkan dengan semua rating alternatif yang ada.

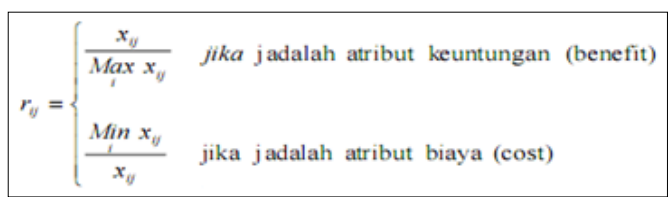

Gambar 1. Rating Kinerja Ternormalisasi

Dimana $r_{i j}$ adalah rating kinerja ternormalisasi dari $\mathrm{ij}$ alternatif $\mathrm{A}_{\mathrm{i}}$ pada atribut $C_{j} ; i=1,2, \ldots, m$ dan $j=1,2, \ldots, n$. Nilai preferensi untuk setiap alternatif $\left(\mathrm{V}_{\mathrm{i}}\right)$ diberikan sebagai:

$$
\mathbf{V}_{\mathrm{i}}=\sum_{\mathrm{j}=1}^{\mathrm{n}} \mathbf{w}_{\mathrm{j}} \mathbf{r}_{\mathrm{ij}}
$$

Gambar 2. Nilai Vi

Nilai $\mathrm{V}_{\mathrm{i}}$ yang lebih besar mengindikasikan bahwa alternatif $A_{i}$ lebih terpilih.

Langkah penyelesaian menggunakan metode Simple Additive Weighting (SAW):

a. Menentukan kriteria yang dijadikan acuan pengambilan keputusan.

b. Menentukan rating kecocokan setiap alternatif pada setiap kriteria.

c. Membuat matriks keputusan $\mathrm{X}$ berdasarkan kriteria, kemudian melakukan normalisasi matriks $\mathrm{X}$ berdasarkan persamaan yang disesuaikan dengan jenis atribut sehingga diperoleh matriks ternormalisasi R.

d. Hasil akhir diperoleh dari proses perangkingan yaitu perjumlahan dari perkalian matrik ternormalisasi $\mathrm{R}$ dengan vektor bobot (Matriks W) sehingga diperoleh nilai terbesar yang pilih sebagai alternatif terbaik sebagai solusi.

Kelebihan dari model Simple Additive Weighting (SAW) dibandingkan dengan model pengambilan keputusan yang lain terletak pada kemampuannya untuk melakukan penilaian secara lebih tepat karena didasarkan pada nilai kriteria dan bobot preferensi yang sudah ditentukan, selain itu SAW juga dapat menyeleksi alternatif terbaik dari sejumlah alternatif yang ada karena adanya proses perankingan setelah menentukan nilai bobot untuk setiap atribut (Sri Kusumadewi, Sri Hartati, Agus Harjoko, Retantyo Wardoyo, 2006).

\section{Metode Analytical Hierarcy Process (AHP)}

Metode AHP adalah sebuah kerangka untuk mengambil keputusan dengan efektif atas persoalan yang kompleks dengan menyederhanakan dan mempercepat proses pengambilan keputusan dengan memecahkan persoalan tersebut ke dalam bagian-bagiannya, menata bagian atau variabel ini dalam suatu susunan hirarki, memberi nilai numerik pada pertimbangan subjektif tentang pentingnya tiap variabel dan mensintesis berbagai pertimbangan ini untuk menetapkan variabel yang mana yang memiliki prioritas paling tinggi dan bertindak untuk mempengaruhi hasil pada situasi tersebut. Metode AHP ini membantu memecahkan persoalan yang kompleks dengan menstruktur suatu hirarki kriteria, pihak yang 
berkepentingan, hasil dan dengan menarik berbagai pertimbangan guna mengembangkan bobot atau prioritas. Metode ini juga menggabungkan kekuatan dari perasaan dan logika yang bersangkutan pada berbagai persoalan, lalu mensintesis berbagai pertimbangan yang beragam menjadi hasil yang cocok dengan perkiraan kita secara intuitif sebagaimana yang dipresentasikan pada pertimbangan yang telah dibuat (Kusrini, 2007).

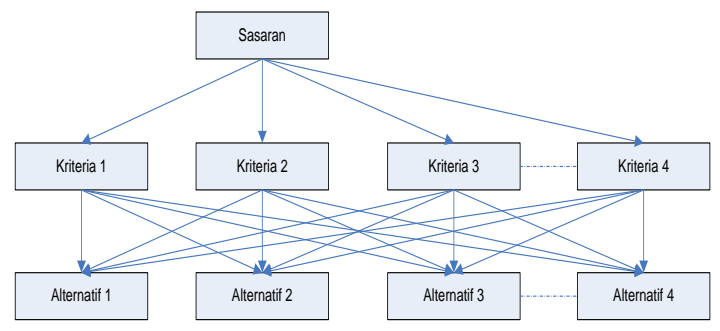

Gambar 3. Analytical Hierarchy Process.

\section{Teknik Pengumpulan Data}

Data yang dikumpulkan terdiri atas data sekunder dan data primer. Data primer berasal dari lokasi pengkajian secara langsung, yang dilakukan melalui wawancara pada staf dan kepala laboratorium komputer kampus STMIK Widya Cipta Dharma Samarinda J1. M. Yamin No. 25 Samarinda. Sedangkan data sekunder diperoleh dengan mempelajari studi literatur yang berupa aturan-aturan tertulis atau dokumen yang ada kaitannya judul penelitian. Selain itu data juga di dapat melalui observasi atau pengamatan langsung pada Laboratorium Komputer Kampus STMIK Widya Cipta Dharma Samarinda Jl. M. Yamin No. 25 Samarinda.

\section{HASIL PENELITIAN DAN PEMBAHASAN}

Sistem pendukung keputusan untuk pemilihan staf laboratorium komputer dengan menggunakan Simple Additive Weighting (SAW) dan Analytical Hierarchy Process (AHP) akan berfungsi sebagai sarana untuk mempercepat pengambilan keputusan di lingkungan manajemen STMIK Widya Cipta Dharma Samarinda. Pengembangan sebuah perangkat lunak untuk sistem pendukung keputusan pemilihan staf laboratorium komputer di STMIK Widya Cipta Dharma Samarinda dengan Metode Simple Additive Weighting (SAW) dan Analytical Hierarchy Process (AHP) mencakup penentuan spesifikasi sistem yang dibutuhkan oleh aplikasi, perancangan antarmuka pengguna. Berikut dapat dilihat tampilan login dan antarmuka pada gambar 4 dan gambar 5.

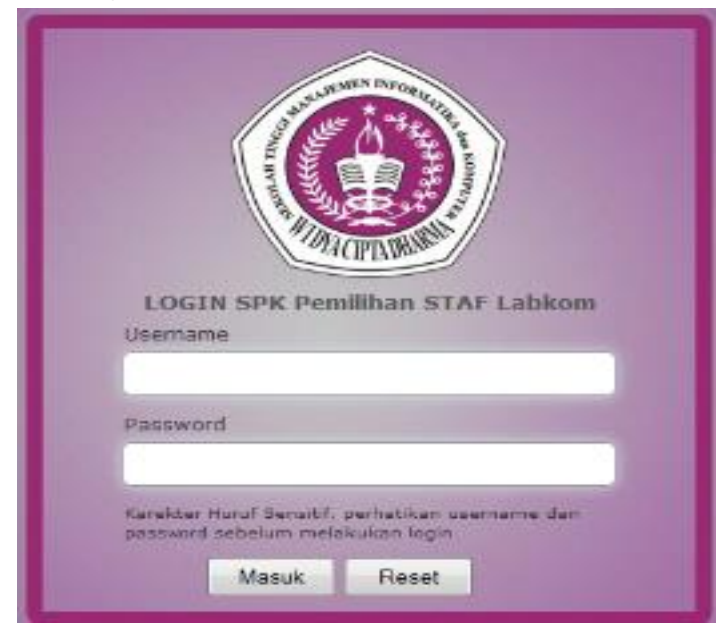

Gambar 4. Login User

Gambar 4 merupakan form login user untuk menjalankan aplikasi pemilihan staf laboratorium komputer. Agar bisa masuk pada tampilan halaman utama aplikasi harus menuliskan user name dan password apabila username atau password salah maka tidak akan bisa melanjutkan. Apabila username atau password benar maka akan tampil ke antarmuka aplikasi seperti gambar 5. 


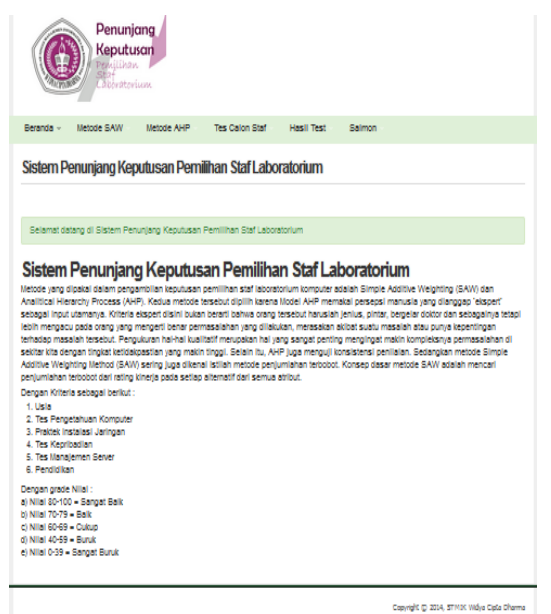

Gambar 5. Antarmuka Aplikasi

Gambar 5 merupakan tampilan halaman utama aplikasi yang terdiri dari dari 5 (lima) menu yaitu menu beranda, menu metode SAW, menu metode AHP, menu tes calon staf dan menu hasil tes.

\section{Tampilan Kriteria SAW}

\section{Kitenia SAW}

\begin{tabular}{|c|c|c|c|c|}
\hline No & Namig Kriteris & Urign & Atriout & Aisi \\
\hline & Usig & Usis Cion Stbi & cost & 国 \\
\hline 2 & Tes Pengetalusun Kompdier, & Tes Pengethusn Kemputer, & berafif & 国 \\
\hline 3 & Prokek / nsagsai Isingen, & Proskek /nstalsis Jarngen, & benalif & 国 四 \\
\hline t & Tes Kegribodilgn & Tes Kepribadian & bengfi. & 国 圆 \\
\hline 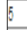 & Tes Margiemen Sever & Tes Margemen Sener & benalit & 国 园 \\
\hline & \begin{tabular}{|l|l|} 
Penciolksn \\
\end{tabular} & Pendidiksn & bersis & 国 \\
\hline
\end{tabular}

Gambar 6. Kriteria SAW

Seperti Gambar 6 diatas merupakan halaman kriteria SAW dimana terdapat tombol Del dan tombol Edit. Apabila user akan mengahapus bobot SAW klik tombol Del dan apabila user akan melakukan perubahan bobot klik tombol Edit.

\section{Tampilan Bobot SAW}

BobotSAW

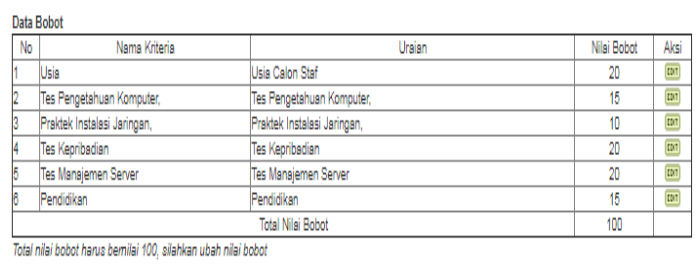

Gambar 7. Bobot SAW
Gambar 7 diatas merupakan halaman bobot SAW dimana terdapat nilai pembobotan masing-masing kreteria dengan total bobot $100 \%$.

\section{Tampilan Hasil Perhitungan SAW}

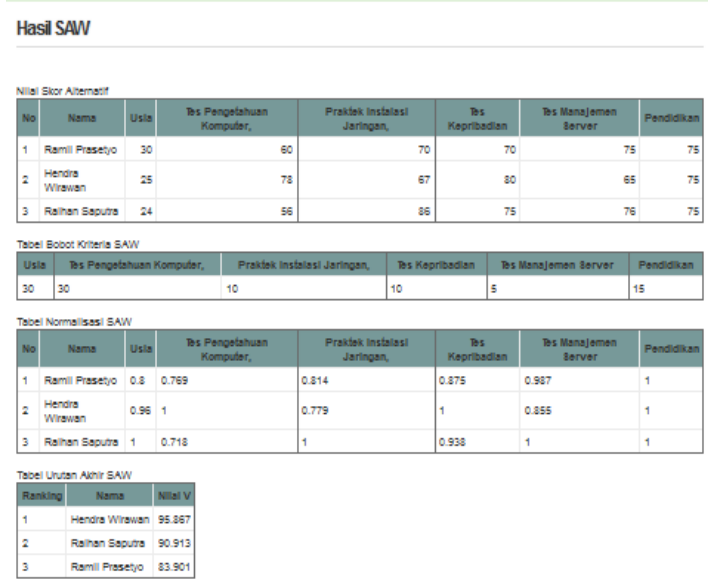

Gambar 8. Hasil Perhitungan SAW

Gambar 8 diatas merupakan tampilan dari hasil perhitugan metode SAW dari 3 (tiga) orang calon staf. Untuk metode SAW calon staf yang direkomendasikan adalah Hendra Wirawan dengan nilai : 95,867 .

\section{Tampilan Kreteria AHP \\ KiteriaAhp}

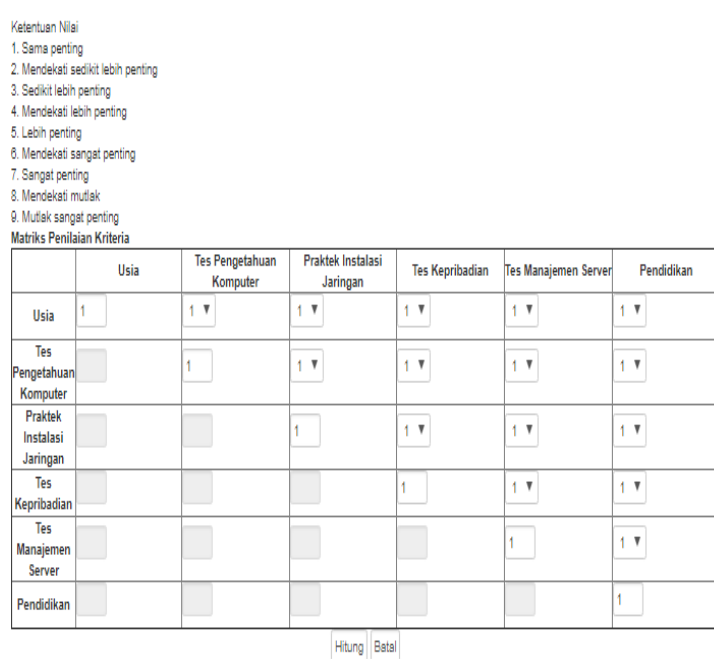

Gambar 9. Kreteria AHP

Gambar 9 diatas merupakan halaman kriteria AHP dimana terdapat tombol Hitung dan tombol Batal. 
Komparasi Metode Simple Additive Weighting (SAW) dan Analytical Hierarchy Process (AHP) Untuk Pemilihan staff laboratorium Komputer STMIK Widya Cipta Dharma Samarinda Salmon dan Bartolomius Harpad

\section{Tampilan Hasil Perhitungan AHP}

\section{HasilAHP}

\begin{tabular}{|c|c|c|c|c|c|c|c|}
\hline IDcalon & I remacalon & Usia Calon & Pengetahuan Kamolter & Prodet varingen & Tes Kegribodina & Varajenen Server & Pendilken \\
\hline \multirow[t]{2}{*}{ OIV } & Rami Pasetio & 30 & 60 & 70 & 70 & 75 & 75 \\
\hline & & Bnok & Ohe & Bak & Bak & Bak & Bak \\
\hline \multirow[t]{2}{*}{ OBB } & Hecua Niraian & 25 & 78 & 67 & 80 & ex & 75 \\
\hline & & Bak & Bak & aves & Saydad baik & avep & Bak \\
\hline \multirow[t]{2}{*}{$m$} & Ranan Saputa & 24 & 30 & 86 & 75 & 76 & 75 \\
\hline & & Sragat bak & Burk & Sargat bak & Bak & Bak & Bak \\
\hline
\end{tabular}

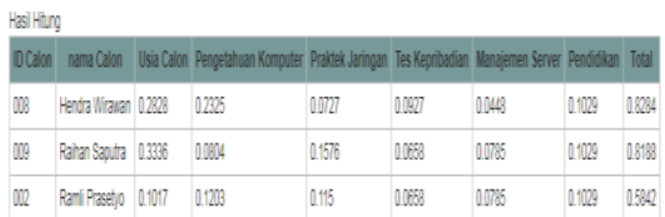

Gambar 10. Hasil Perhitungan Metode AHP

Pada gambar 10 merupakan tampilan dari hasil perhitungan metode AHP dimana calon staf yang dapat direkomendasikan menjadi staf laboratorium komputer adalah Hendara Wirawan dengan nilai : 0,8284.

\section{PENUTUP}

\section{Kesimpulan}

Kesimpulan dari hasil penelitian mengenai Komparasi Metode Simple Additive Weighting (SAW) dan Analytical Hierarcy Process (AHP) Untuk Pemilihan Staf Laboratorium Komputer Pada STMIK Widya Cipta Dharma Samarinda adalah sebagai berikut:

1. Pemilihan Staf Laboratorium Komputer Pada STMIK Widya Cipta Dharma Samarinda dilakukan dengan metode Simple Additive Weighting (SAW) dimana tahapannya mencari penjumlahan terbobot dari rating kinerja pada setiap alternatif pada semua atribut dan juga dengan menggunakan metode Analytical Hierartical Process (AHP) dimana tahapan nya dimulai dari mendefenisikan masalah dan solusi, membuat struktur hierarki, membuat matriks berpasangan, menghitung nilai eigen, dan memeriksa konsistensi hierarki hingga didapat keputusan dari alternatif yang sesuai.

2. Kriteria yang digunakan dalam menerapkan metode Simple Additive Weighting (SAW) dan Analytical Hierarcy Process (AHP) terdiri dari 6 (enam) kriteria yaitu : Usia, Tes Pengetahuan Komputer, Tes Praktek Jaringan, Tes Kepribadian, Tes Manajemen Server dan Pendidikan.

3. Hasil rekomendasi yang dihasilkan dari metode Simple Additive Weighting (SAW) dan metode Analytical Hierartical Process (AHP) merekomendasikan nama calon staff yang sama pada ranking pertama (ke-1), tetapi menghasilkan nama calon yang berbeda pada ranking ke-2 dan ke-3. Karena adanya variabel yang membedakan dari proses perhitungan masing-masing metode.

4. Dari kasus pemilihan staff laboratorium metode yang sangat efektif menghasilkan rekomendasi adalah metode Analytical Hierartical Process (AHP) Karena Pemilihan staff laboratorium ini melibatkan banyak sub-kriteria, dimana AHP dianggap tepat untuk mewakili pemikiran alamiah yang cenderung mengelompokkan elemen sistem ke level-level yang berbeda dari masing-masing level berisi elemen yang serupa sehingga lebih baik digunakan untuk pemilihan staff laboratorium yang melibatkan banyak kriteria dengan level hirarki yang berbeda. Selain itu, metode AHP juga menyediakan skala pengukuran dan metode untuk mendapatkan prioritas untuk semua hirarki kriteria, karena 
masing masing kriteria memiliki prioritas yang tidak sama.

\section{Saran}

1. Melakukan pengujian secara berkala pada sistem yang dihasilkan dan dapat membuat sistem yang dapat dikustomisasi pada sesuai dengan perubahan.

2. Kedepannya dapat dilakukan perbandingan dengan menggunakan tambahan metode sebagai alternatif seperti metode TOPSIS agar didapat hasil yang lebih maksimal jika 3 (tiga) metode di jadikan satu dalam pembuatan sistem.

\section{UCAPAN TERIMAKASIH}

Dibiayai oleh:

Direktorat Riset dan Pengabdian Masyarakat Direktorat Jenderal Penguatan Riset dan Pengembangan Kementerian Riset, Teknologi, dan Pendidikan Tinggi sesuai dengan Kontrak Penelitian Tahun Anggaran 2018.

\section{DAFTAR PUSTAKA}

Huda, Syamsul (2011). Aplikasi Optimasi Pemilihan Lokasi Yang Optimal Dengan Hybrid Analysis Fuzzy Analytical Hierarchy Process. Magister Management Technology. Institut Teknologi Sepuluh Nopember (ITS). Surabaya.

Kusrini. (2007). Konsep Dan Aplikasi Sistem Pendukung Keputusan. Yogyakarta: Andi Offset

Kusumadewi, dkk. (2006). Fuzzy MultiAtribute Decision Making (MADM). Graha Ilmu. Yogyakarta.

McLeod Jr, Raymond, dan Schell George P. (2007), Management Information System $10^{\text {th }}$ Edition. New Jersey :
Prentice Hall

Nugroho Joko Usito (2013). Sistem Pendukung Keputusan Penilaian Proses Belajar Mengajar Menggunakan Metode Simple Additive Weighting (SAW). Tesis Pasca Sarjana Sistem Informasi. Universitas Diponegoro. Semarang.

Ravindratnath (2003), Decision Support Systems and Data Warehouses. New Delhi, New Age International.

Sauter, Vicky L. (2010), Decision Support Systems for Business Intelligence $2^{\text {nd }}$ Edition, New Jersey, John Wiley \& Sons.

Turban Efraim, Aronson Jay E. , dan Liang Ting Peng (2005), Decision Support System And Intelligent Systems $7^{\text {th }}$ Edition, New Jersey, Prentice-Hall, Inc.

Turban, Efraim., Sharda, Ramesh.,\& Delen, Dursun., (2011), “Decision Support and Business Intelligence Systems", Edisi 9, Pearson Education Inc

Tominanto (2012). Sistem Pendukung Keputusan Dengan Metode Analytical Hierarchy Process (Ahp) Untuk Penentuan Prestasi Kinerja Dokter Pada RSUD. Sukoharjo. APIKES Citra Medika Surakarta 